\title{
1 HUMANIDADES, HUMANISMOS Y HUMANISMO PEDAgógICO
}

\author{
Ángeles Galino Carrillo \\ UNED, Facultad de Edacación \\ Catedratica de Historia de la Edacación \\ Ex Directora General de Ordenación Acadénica
}

\section{HUMANIDADES}

La densa polisemia del término Humanidades aconseja una rápida recapitulación inicial. Consideramos a continuación algunas acepciones del término, todas ellas respaldadas por sólida base semántica.

Humanitas litterarum. El impulso fundamental de las Humanidades en el Renacimiento se alimentó de la Literatura Clásica, griega y romana, con los sucesivos descubrimientos de poetas, prosistas y pensadores. En el fondo, logos, pensamiento y palabra.

La Humanitas moral. Con el binomio Sócrates-Platón y Aristóteles, y más tarde con los estoicos que integran el grupo de los llamados directores de conciencia, entre los que destaca Séneca y, desde luego, con Cicerón -pero no únicamente con él- se llega a una modalidad de la humanitas y a un concepto más elaborado de la misma, que incluye y rebasa al mismo tiempo el cultivo de las letras. Exige el íntimo, pero muy concreto, cultivo del ánimo, una disciplina de las pasiones y la conquista de una personalidad superior, caracterizada por las notas de afabilidad, benignidad, cordialidad, clemencia, comprensión, amor, cortesía, respeto de sí mismo y de los demás. Respeto debido 
no sólo a los nobles y sabios, sino también a la gente vulgar (De officiis, 1,7 y ss). En el fondo, SABiduría.

La Humanitas estética. Florece paralelamente a la humanitas literaria y genera las nuevas creaciones del Renacimiento a partir del genio artístico de la Grecia clásica y de la diáspora helenística. En el fondo, tò kalón, belleza.

La Humanitas política. Dado que "las obligaciones que contribuyen a la conservación de la sociedad y unión de los hombres se han de anteponer a las que provienen del conocimiento y de la sabiduría" (De officiis, 1, 44), el bien de la sociedad se convierte en ley suprema de la humanitas política, a la que, en último término, se han de ordenar las dimensiones literarias, morales y estéticas antes citadas. En el fondo, Politela para Grecia, LEx para Roma.

Sobre el fundamento de la paideia literaria y la filosófica, los grandes autores de Grecia y Roma dedicaron sus mejores páginas a la formación del hombre y al establecimiento de los valores que concibieron como vinculados esencialmente a la plenitud humana: la eticidad, la socialidad y la apertura a la trascendencia.

\section{EL HUMANISMO. EVOLUCIÓN SEMÁNTICA}

Ciertamente, los griegos y los latinos habían legado a la humanidad un ideal del hombre y para el hombre, de actitudes, de puntos de vista, de modos de mirar las cosas y la naturaleza, de una concepción de la vida; toda una concepción antropocéntrica en la que se injertó la concepción cristiana del mundo y, en muchos casos, teocéntrica. Y ésta es la raíz.

Se considera humanista a la persona instruida en estas letras humanas. El término aparece en el siglo XV y fue de uso común en el siglo XVI. El cultivo y conocimiento de las letras humanas constituyó el patrimonio heredado y recreado por los humanistas del Renacimiento. En España se dio el gran desarrollo que cimentó las creaciones del más tarde denominado Siglo de Oro.

La Humanitas pedagógica, un ideal de educación humanística que, apoyado en la paideia, intenta relacionar la cultura literaria con los aspectos educativos que se ordenan a la perfección humana. La fuerte reacción cultural y pedagógica del Renacimiento frente a la Edad Media concibe el aprendizaje del griego y el latín como la propedéutica ideal para el cultivo de la inteligencia. El trato con los clásicos se considera el camino más apto para adquirir una filosofía de la vida práctica, ética, política: excelentes guías de conducta y, en resumen, autorizados y modernos magistri vitae. 
En el fondo, PaIdeIa para Grecia, humanitas para Roma, formación, educación.

Humanismo. El siglo XIX supone un nuevo paso en la evolución semántica. En la acepción de uso hoy corriente es un término acuñado por los neoclásicos alemanes de fines del XVIII y los románticos a principios del siguiente.

El humanismo en esta acepción se ocupa de la literatura, los valores y problemas humanos en general, probablemente por contraposición a las ciencias positivas emergentes.

Hay que distinguir entre el estudio de las Humanidades tal como se concibieron en la antigüedad y el Renacimiento hasta el siglo XVIII, y el Humanismo como cultivo y conocimiento de aquellos aspectos de la cultura en lo que tienen de más específicamente humano: la filosofía y el estudio de la lengua y de las creaciones literarias, preponderantemente.

La reorganización que hizo el siglo XIX de las facultades universitarias pasa a las nuevas facultades de ciencias materias como la física que estaba en la de Artes y deja la Filosofía y las denominadas, en principio, Letras para las facultades que por mucho tiempo se llamaron así.

En la reivindicación actual de los estudios humanísticos hay una cierta confusión entre humanismo y humanidades.

El uso los distingue.

Al humanismo del siglo $\mathbf{X X}$ le debemos el ser portador de grandes ideales civiles: la dignidad humana, de la que Juan Pablo II se ha hecho, más que eco, heraldo en nuestros días, la libertad, la justicia social, la solidaridad, la nueva dignidad de la mujer (paridad, diferencia, complementariedad, reciprocidad). Pero todo ello en un horizonte donde la vida humana ha sido objeto de ultrajes sin precedentes, donde la idea de que el hombre es cosa sagrada para el hombre carece de sentido. Por ello, a esa corriente del humanismo de nuestro tiempo se le ha calificado de humanismo inhumano, mientras la dialéctica de sus diferentes creaciones literarias y artísticas se contigura como una auténtica expresión de la tragedia del humanismo.

Laín Entralgo formuló un concepto de humanismo, a partir de la educación. Por cierto que se le acaba de distinguir precisamente por su condición de Médico humanista.

Mi fórmula, dice Laín, parte de una distinción entre dos niveles del humanismo: un humanismo "por extensión" o básico y otro "por intensión" o superior. 
El humanismo por extensión consiste en saber responder con una mínima precisión a cinco interrogaciones:

1. ¿En qué mundo vivo, en tanto que ciudadano de él? Creencias, ideas, esperanzas, tensiones, conflictos y temores en él vigentes; muy especialmente, en la fracción de él que solemos llamar "occidental".

2. Haciendo mi vida en el mundo me encuentro con cosas. ¿Qué son las cosas, desde el "Big-Bang" originario hasta el universo actual, desde la partícula elemental hasta el antropoide?

3. Haciendo mi vida en el mundo me encuentro también con los demás hombres, organizados en grupos humanos. ¿Qué son los hombres humanos y cuáles son los más importantes?

4. ¿Qué soy yo, en tanto que hombre? ¿Qué enseñan hoy a tal respecto las ciencias positivas y la filosofía?

5. Para que yo sea el hombre que soy, ¿qué ha tenido que pasarle a la especie humana, desde su aparición hasta hoy? Dará la respuesta una sucinta descripción sistemática de las principales formas de vida de la humanidad, muy en especial las que desde la Grecia antigua integran la historia del mundo occidental'.

\section{EL RECLAMO HUMANISTA \\ DE LA SOCIEDAD ACTUAL}

El pasado 22 de octubre la Ministra presentó a la prensa el "Plan de mejora de la enseñanza de las Humanidades en el sistema educativo español", incorporando el proyecto de reforma del Real Decreto de Enseñanzas Mínimas en la Educación Secundaria Obligatoria de Geografía e Historia y Lengua y Literatura.

El humanismo del futuro. Hay que advertir sobre una cuestión importante de fondo respecto a qué Humanidades precisan nuestros escolares para encarar el siglo XXI. El Humanismo necesario incorpora ideas y valores de nuevo cuño distintos a los establecidos hasta ahora. El hombre del mañana sentirá y estará en un mundo diferente. La sustitución del trabajo por máquinas convierte el trabajo cada vez más en algo inmaterial y acentúa el carácter

\footnotetext{
'Pedro lain Entrai.go, ABC, Madrid, 19 de julio de 1996 (De una conferencia en la Universidad de El Escorial).
} 
cognitivo de las tareas. El trabajo se desmaterializa. El Humanismo del futuro debe responder a nuevos retos.

La definición de cuál es o puede ser el Humanismo de nuestro tiempo y del futuro a medio plazo no puede hacerse sólo desde el Ministerio de Educación y Cultura. Es una cuestión básica a la que los educadores y pedagogos no podemos renunciar.

Coordinación, unidad del sistema, alcanzar acuerdos y lograr el consenso; responsabilidades todas que corresponden al Ministerio y que justifican su existencia. En suma, política de educación.

Pero iniciativa educativa y cultural, visión de futuro, y la configuración de la educación que a ello ha de responder, eso nos corresponde. No pretendiendo un monopolio ideológico, sino participando, si llega el caso, en ese debate nacional sobre la educación que algunos preconizan. Y que en realidad está ya planteado. Llegado el momento, ni Vives ni Jovellanos renunciaron a aportar el giro innovador que sus respectivas contribuciones dieron a los Humanismos de su tiempo².

\section{¿HACIA UN HUMANISMO PEDAGÓGICO GLOBAL?}

Los griegos que crearon la democracia también inventaron ese producto espléndido de la cultura que es la paideia "la educación, como la única trayectoria mental que permite capacitar a los hombres para ser verdaderamente democráticos y creadores". El ideal de una formación humanística se relaciona con el concepto de humanismo, esa palabra que, a juicio de Lledó, merece ser redimida de su preterición, por "equivocaciones u olvidos de lo que el humanismo tiene de creador, mirador del futuro, instalación en el mundo y, en una palabra, amor al mundo". Porque los descubrimientos científicos y el desarrollo tecnológico han marcado la Época Moderna, mientras los saberes de Humanidades aparecen, a partir de la Ilustración, como menos útiles.

Sin embargo, lo científico, lo tecnológico y lo humanístico, como productos humanos que son, se entrelazan y correlacionan. Es una pérdida enorme para la Humanidad que sigamos siendo víctimas de la anacrónica división en Ciencias y Letras. Los avances científicos y tecnológicos exigen

\footnotetext{
${ }^{2}$ Boletín del Colegio de Licenciados, noviembre 1997. Editorial, p. 1.
} 
no sólo nuevos conocimientos y habilidades para su empleo, su uso suscita siempre nuevas cuestiones éticas y legales. Estamos de acuerdo con el último Informe Mundial sobre la Ciencia, publicado por la Unesco: "A medida que la ciencia y la tecnología avanzan a ritmo vertiginoso, aumenta la capacidad de afectar a la sociedad humana para bien o para mal. Es lógico, pues, que cada vez causen más preocupación las cuestiones relacionadas con la ética, los derechos humanos o la imagen pública de la ciencia ${ }^{3}$.

¿Cómo deben formarse un hombre, una mujer de hoy, para llegar a ser libres, responsables, solidarios con los problemas del otro como pide el humanismo actual, tolerantes y creativos en el seno de las sociedades multiculturales, multiétnicas, multiéticas y altamente competitivas, dominadas por la tecnociencia? ¿Cómo educar en el pensamiento abstracto y simbólico, en la capacidad crítica, en la creación intelectual y artística? ¿Cómo acompañar en el ejercicio progresivo de la libertad, en la formación de la conciencia moral, en la capacidad de diálogo consigo mismo y en la participación cívica?

Reconozcamos que, ante preguntas como éstas, los educadores somos también educandos. Los avances de la ciencia y la tecnología están produciendo una aceleración de la Historia que hacen del tiempo que vivimos un riguroso presente-futuro como ya lo escribió en castellano el escritor rumano Vintila Horia. Pero si pensamos en el tiempo vital de los alumnos, le cuadra mejor futuro-presente: un futuro ya presente. Ni los resultados de los progresos de la tecnología y de la ciencia son siempre conocidos, ni mucho menos aún el rumbo que tomará la Historia está sujeto a leyes predecibles. Sin embargo, la esfinge, ahora más que nunca, sigue pronunciando para nosotros el misterioso oráculo: "Todo educador está obligado a trabajar con visiones anticipatorias".

El enfoque se propone responder a objetivos que se plantean en la sociedad contemporánea o, si se quiere, posmoderna y que rebasan, por definición, el contenido de cada una de las materias -tradicionales o nuevas- del currículo. Más allá de los conocimientos particulares, la vocación básica de este que propongo llamar humanismo global, susceptible, por supuesto, de distintas realizaciones modales, exige ordenar explícitamente la educación a la persona en las dimensiones de su mismidad y de su socialidad.

Respeto al hombre en sus exigencias universales (como quiso Kant), pero al mismo tiempo -superando todo abstractismo centralizador y colonizador-reconocimiento de la diversidad de los grupos culturales; y de las diferencias personales.

\footnotetext{
${ }^{3}$ Mennon, M.K.G. (1995): Informe Mundial sobre la Ciencia, UNESCO, ed. Santillana, Madrid, Introduccion, p. 9.
} 
Acceso cognitivo y experiencial al mundo científico-tecnológico en el que estamos inmersos y formación de criterios para abrirse a sus posibilidades y límites.

Interés por la aventura del hombre sobre la tierra (ontogénesis y filogénesis): apertura a las aportaciones de las ciencias y a las respuestas de la filosofía, la historia, el arte, las vivencias religiosas, ¿qué soy yo en tanto que ser humano?

Sentido e importancia de las relaciones interpersonales como encuentro conflictivo y/o como espacio que propicia la creatividad de las personas y multiplica indefinidamente las posibilidades de servicio, gozo, gratuidad y entrega.

Fomento de las capacidades creativas como uno de los retos más fuertes que se plantearán con toda urgencia en los años inmediatos. "En épocas de crisis sólo la imaginación es más importante que el conocimiento" (Albert Einstein).

Aproximación a la realidad de los grupos sociales y políticos. Conocimiento del proceso histórico que ha forjado la identidad del propio país. Noción de las identidades culturales del escenario socio-político del mundo. Tensiones o conflictos actuales. Tolerancia y convivencia política.

El humanismo a que nos referimos adopta intencionalmente la formación de la conciencia y la del pensamiento crítico de quienes han de asumir responsablemente y con creatividad las instancias del mundo contemporáneo. Privilegia la adquisición de conocimientos y experiencias fundamentales para el conocimiento de sí y la mejor comprensión de las relaciones interpersonales. Se esfuerza en hacer progresivamente fecundo y solidario el comportamiento con el otro, con los otros.

\section{¿PODRÁ EL HUMANISMO GLOBAL ARTICULAR LA EDUCACIÓN QUE HOY SE REQUIERE?}

Articular tiene aquí el sentido de una integración orgánica de la función docente y educadora. No una mera yuxtaposición en el puzzle de un programa, sino una articulación hecha desde el significado que cada área o materia ha de tener para la formación de la personalidad. Un humanismo que acoge los nuevos saberes y descubre las dimensiones que colaborarán a la madurez personal del sujeto que los cursa. Ésta es una responsabilidad en la que han de converger los esfuerzos de tres niveles: la administración educativa, los 
teóricos de la ciencia, el humanismo y la educación y, desde luego, los profesores, no como meros ejecutores de técnicas docentes, sino como profesionales de la docencia y de la educación. No hace falta ponderar aquellos métodos de investigación que postulan la actuación sinérgica de teóricos y prácticos.

Hoy me permito apuntar, más que a dos temas, a dos yacimientos de cuestiones. La primera, cómo responder humanísticamente a un mundo dominado por las ciencias de la naturaleza, no en el sentido de la vieja Historia Natural, sino de los impensables descubrimientos científicos a que estamos asistiendo, y a los correspondientes desarrollos tecnológicos, así como a las formidables capacidades que proporcionan las continuas interacciones entre ambos.

La otra cuestión arranca de la función que corresponde a los pedagogos ante los problemas que hoy preocupan e inquietan a padres y educadores, $\mathrm{y}$ a la sociedad en general, a veces tan ajenos a las investigaciones, artículos, estudios y notas que encontramos en las revistas especializadas de nuestro entorno. La diatriba no se refiere a la investigación pura como tal, sino -casi no me atrevo a decirlo- a la penuria de atención para el enorme reto que hoy pone en crisis la educación actual.

En el primer caso nos hallamos ante el desencuentro -o ignorancia recíproca- entre la cultura científica y la cultura humanística: una cultura, la nuestra, amputada por ambos lados. ¿Cómo superar este dualismo traumático, para emplear la gráfica expresión de Martín Municio? Él piensa que la cultura actualmente deseable sería una "Cultura global".

Mis preguntas no van hoy precisamente en su línea, por lo demás muy sugerente. Me sitúo propiamente en lo que Laín denominaba humanismo de extensión frente al humanismo de intensión, propio de especialistas.

No me cuestiono las materias que han de entrar en la Enseñanza Secundaria Obligatoria, puesto que tiene y ha de tener su lugar la alfabetización científica que proporcione la enseñanza formal necesaria para los ciudadanos de sociedades democráticas que han de participar en decisiones que afectan a la comprensión pública de la ciencia. Si se piensa en los niveles de dominio cultural y dominio funcional de estos lenguajes, el primero sería obligado para todos, es el propio de la Enseñanza Secundaria Obligatoria, y el segundo exigible para quienes van a cursar estudios superiores.

Lo mismo digo del lenguaje matemático, cuya potencia expresiva es, como sabemos, inherente a la naturaleza de este conocimiento. El aprendizaje y contacto con las diferentes formas de expresión matemática -numérica, geométrica, algebraica, lógica, gráfica y probabilística- permiten 
explicar relaciones y predecir hechos, tanto del dominio de las ciencias exactas como de otras, y hacerlo de forma precisa y rigurosa.

Las rápidas conquistas de la tecnología en general, que se desarrolla en función de la cultura mediática, plantean de modo acuciante las relaciones entre el mundo real y el mundo virtual. Muchos son los problemas que esto desata para una intervención eficiente, a fin de educar en las habilidades requeridas para moverse en el uso de los medios de información y de informatización con sentido crítico y naturalidad. Tanto por lo que se refiere a los espacios de trabajo como a los dedicados al ocio.

\section{LA MIRADA HUMANA}

Mi reflexión va en el sentido de cómo han de tratarse para que, superando una cultura fragmentada o de mosaico, cooperen a la formación humana con las grandes posibilidades que para ello tienen; contribuyan, digo, a la formación humana, en este caso concreto humanística, con un humanismo actual, al que buena parte de la sociedad, entre la que me encuentro, no quiere renunciar.

¿Cuál sería entonces la base humanística que habría de proporcionar esa capacidad integradora y articuladora que le pedimos al humanismo global?

Pensemos que el humanismo ha sido capaz de acoger grandes movimientos culturales y aun de encarnarlos. Sin embargo, la situación de hoy es particularmente crítica porque el conocimiento que merece crédito universal es el tecnológico-científico; el que se está imponiendo en la educación. Ahora bien, teniendo en cuenta el patrimonio de más de treinta siglos de Historia que sustentan la cultura occidental -me refiero al humanismo griego-latinojudeo-cristiano- me atrevo a reclamar una mirada humana para la complejidad creciente del mundo actual. Una mirada humana o, mejor, humanística que habría que guiar la educación global desde tres claves inesquivables.

- La educación se ordena a la persona. La antropología pedagógica que subyace al empeño de un humanismo global, dialoga con las ciencias positivas del hombre y mantiene abierto el diálogo con las cuestiones radicales de la filosofía y de la teología. Nunca es ociosa la pregunta por el hombre, por la mujer. En ningún caso ha de sacrificarse el ser humano a las ideologías. El humanismo global sostiene la primacía del sujeto que se educa. Todo lo humano es personal, como se ha reivindicado tantas veces entre nosotros "a pesar de que -en frase de Julián Marías- se lleva más de dos siglos intentando olvidarlo y destruirlo"4.

\footnotetext{
"Julián Marías, ABC, 17 de agosto de 1995
} 
El educador ha de acoger la vuelta del sujeto, que hoy en día empieza a darse con cierta decisión.

- El drama fundamental del humanismo contemporáneo es su desvinculación de la ética, y ha despreciado la ética porque carece de norte. La libertad es una realidad "fontal" de quien "se hace" en ella, y necesita ser educada. El sujeto que vuelve "es la persona moral, la forma más entrañable y digna y consistente de entender el sujeto". Un sujeto abierto al otro y a los otros, como si no se pudiera ser bueno si no se actuara en favor de alguien. Ser libre no es una propiedad gratuita recibida sin esfuerzo".

- La humanitas clásica se ocupó de las virtudes sociales y políticas. Hoy la formación en la ciudadanía regional, estatal y mundial se inscribe, además de lo dicho, en el horizonte de la mundialidad.

- Educación de los sentimientos. En frase de Antonio Blanch, la penumbra en que hemos tenido dimensiones fundamentales del ser humano ha traído el descuido de las dos únicas facultades anticipatorias que tiene el hombre: el deseo y la imaginación. Contra lo que se pudiera pensar, hay demasiados analfabetos sentimentales en nuestra cultura. Se puede y se debe introducir una pedagogía de los sentimientos (o, mejor, de la inteligencia afectiva, o de la inteligencia sentiente, en frase definitoria de Zubiri), mediante la iniciación en lenguajes no conceptuales como el arte, la literatura y la música, junto al rigor de los razonamientos científicos. El universo que la persona habita no es exclusivamente físico ni intelectual, es también imaginario y deseante. Modos pedagógicos de introducir en una humanitas literaria actual. Las capacidades creativas están en estrecha relación con el sentimiento y la expresión artística. Pero no sólo. La civilización contemporánea es el resultado de creatividad muy diversa.

- La educación intercultural y multicultural es una debatida cuestión, absolutamente actual y no bien resuelta, a la que la UNED ha dedicado especial atención. Congresos, reuniones y publicaciones. 


\section{RESUMEN}

La autora reflexiona sobre lo que podría ser hoy una educación humanista ¿Cómo deben formarse un hombre, una mujer hoy? A partir de la mirada retrospectiva a la evolución semántica de los conceptos de Humanidades, Humanismo y Humanismos del siglo $X X$, se ilumina el carácter de un humanismo pedagógico actual: un humanismo de extensión o global frente al de intensión, propio de los especialistas. Más allá de los conocimientos particulares este humanismo susceptible de distintas realizaciones modales, ordena explicitamente la educación a la persona -el sujeto agente de su educación- en las dimensiones de la mismidad, la socialidad y la transcendencia. Desde el mundo reelaborado de las llamadas "letras" acoge la realidad científico-tecnológica actual y los criterios para abrirse a sus posibilidades y límites; introduce en el conocimiento de las identidades culturales propias y en las del escenario socio-político del mundo; cultiva las relaciones interpersonales y civicas; educa los sentimientos; fomenta las capacidades creativas.

Palabras clave: Humanismo. Humanismos del siglo XX. Humanismo pedagógico. Humanismo intensivo o global. Mundo científico-tecnológico. Capacidades creativas. Educación de los sentimientos.

\section{ABSTRACT}

The author reflects on what humanist education of the feelings could be today. How should present men and women be educated? Starting from the retrospective glance on the semantic evolution of the concepts: $X X$ century humanities, humanism and humanisms, the character of the present pedagogical humanism is enlightened: a global humanism or a humanism of extension facing the humanism of intensity, characteristic of specialists. Beyond particular knowledge, this humanism open to different ways of realisation refers education explicitly to the person-responsible of his or her education- on the dimensions of the self, sociality and transcendence. From the reshaped world of the so-called "Arts", it receives the present scientific-technological reality and the criteria to open to their possibilities and limits; it leads to the knowledge of the own cultural identities and to the socio-political world scenery; it cultivates interpersonal and civic relationships, it nurtures feelings and promotes creative abilities.

Key words: Humanism. Twenty century humanisms. Pedagogical humanism. Global humanism. Humanism of intensity. Scientific-technological world. Creative abilities. Education of feelings. 